\title{
Respiratory Health of Artisanal Miner of Lwisha in Katanga/DR Congo
}

\author{
Léon Kabamba Ngombe ${ }^{1,2}$, Nlandu Roger Ngatu3 ${ }^{3}$ Nyembo Mukena Christophe ${ }^{1}$, \\ Benjamin Kabyla Ilunga ${ }^{2,4}$, Stanis Wembonyama Okitotsho ${ }^{4,5}$, \\ Jean-Baptiste Kakoma Sakatolo4, Brigitta Danuser6, Oscar Luboya Numbi1,4,5
}

${ }^{1}$ Department of Research, School of Nursing of Lubumbashi, ISTM, Lubumbashi, Congo

${ }^{2}$ Faculty of Medicine, Department of Public Health, Unity of Toxicology, University of Kamina, Kamina, Congo

${ }^{3}$ Department of Environmental Medicine, Kochi University Medical School, Nankoku, Japan

${ }^{4}$ School of Public Health, Department of Public Health, University of Lubumbashi, Lubumbashi, Congo

${ }^{5}$ Faculty of Medicine, Department of Pediatry, University of Lubumbashi, Lubumbashi, Congo

${ }^{6}$ Service of Occupational Medicine, Institute for Work and Health, University of Lausanne and Geneva, Lausanne, Switzerland

Email: leonkab@hotmail.com

How to cite this paper: Ngombe, L.K., Ngatu, N.R., Christophe, N.M., Ilunga, B.K., Okitotsho, S.W., Sakatolo, J.-B.K., Danuser, B. and Numbi, O.L. (2016) Respiratory Health of Artisanal Miner of Lwisha in Katanga/DR Congo. Open Access Library Journal, 3: e3233.

http://dx.doi.org/10.4236/oalib.1103233

Received: November 15, 2016

Accepted: December 9, 2016

Published: December 12, 2016

Copyright $\odot 2016$ by authors and Open Access Library Inc.

This work is licensed under the Creative Commons Attribution International

License (CC BY 4.0).

http://creativecommons.org/licenses/by/4.0/

\section{Abstract}

Objective: To determine the prevalence of respiratory symptoms and make an awareness about the harmful effects of ores dust in the Artisanal miner in the city of Lubumbashi, Katanga province, in the Democratic Republic of the Congo (DRC). Method: In total, 104 artisanal miners have been recruited in an exhaustive manner with 122 administrative officers in the town hall of Lubumbashi, responsible for collecting the taxes in the Stations of the bus as the control group. Respiratory symptoms were collected using a standardized questionnaire. To determine the association between the characteristics of the miners and respiratory symptoms reported, a multi-analysis combined with the test of logistic regression has been privileged. Results: The prevalence of the respiratory symptoms was markedly higher in the artisanal diggers, as compared with the group that controls: wheezing $(37.5 \%$ vs. $7.4 \%)$, shortness breathing after effort $(26.9 \%$ vs. $3.3 \%)$, cough $(29.8 \%$ vs. $12.3 \%)$, asthma ( $24 \%$ vs. $1.6 \%)$, rhinitis ( $20.2 \%$ vs. $14.8 \%$ ), conjunctivitis ( $16.3 \%$ vs. $9.8 \%$ ), and eczema (34.6\% vs. $2.5 \%)$. After adjusting for age and education level, digger as occupation was strongly associated with a higher risk of developing respiratory and skin problems ( $p$ $<0.05)$. Conclusion: The study revealed that artisanal miner's professions, as practiced in Lubumbashi, without any protection against dust, have a negative impact on the respiratory health. It proves to be very important to organize a teaching specialized in Occupational Medicine that can train some physicians with an established expertise having to answer if it is needed to be enormous in qualified staff in this area considered at respiratory risk. 


\title{
Subject Areas
}

\author{
Epidemiology
}

\section{Keywords}

Artisanal Miners, Prevalence, Ores of Dusts, Respiratory Health

\section{Introduction}

Small-scale mining has become an activity in full expansion in Katanga and in many African countries [1] [2] [3]. Currently, it is estimated that about 13 - 14 million people of more than 50 under-developed countries are engaged in mining operation in small scale [1] [2] [3]. Occupational exposure to dusts is a well-known phenomenon, especially in the under-developed countries [4] [5]. The emissions of dust are high in the careers and this constitutes a major source of air pollution [6]. The mining sector in Katanga has traditionally been occupied by the Gecamines which is a public company that has taken the succession of the MINING union of the High Katanga in the industrial exploitation of ores. The GCM has made the Democratic Republic of the Congo become the first world producer of copper and cobalt. Toward the end of the 1980s and early 1990s, the decline of the Gecamines was precipitated by a series of problems. As well, the mining activity craft, in the province of Katanga, finds its origin in the collapse of the industrial fabric (Gecamines), pushing the population toward the activities of survival. The former miners first and, subsequently, the majority of the mass worker in this province, are gradually reconverted into mining artisans [7]. Unfortunately, it takes place in an informal framework, in the margin of the legal and regulatory provisions in the matter [8]. The absence of means of protection, individual or collective (mask, headset, boots, goggles, gloves, etc.) as well as the use of operating dangerous practices that characterize this activity is likely to cause a number of health problems. In Congo, the term miner is commonly used to designate the operator's artisanal mining. It is a worker who operates the deposits with manual processes, rudimentary or non-industrial. Unlike other profession, work in a dusty environment has the risk of inhalation of particles (silica) which may lead to different respiratory diseases [9] such as chronic bronchitis, emphysema, acute and chronic silicosis, cancer of the lung. According to Urom [10], the majority of respiratory symptoms found among workers in quarries were composed of non-productive cough, chest pain, catarrhes and dyspnoea.

Nevertheless, in the scientific literature, there are epidemiological studies on the effects of exposure to dust concerning minors, well diggers, tailors ceramics, the briquiers. Few studies have concerned the artisanal miners of the under-developed countries. As well, the purpose of this work was to determine the prevalence of respiratory symptoms and make an awareness about the harmful effects of dust among artisanal miners in the city of Lubumbashi, Katanga province, in the Democratic Republic of the Congo (DRC). 


\section{Materials and Methods}

\subsection{Type of Study, Framework and Study Population}

It is a cross-sectional study descriptive and analytical in the population of the artisanal mining of Lwisha village in the city of Lubumbashi in Katanga. The population studied was composed of the miners and a control group. In total, 140 miners with more than a year have been recruited and among them, only 104 have participated in the study. The control group is composed of 122 administrative officers in the town hall of Lubumbashi, responsible for collecting the taxes in the bus Stations with more than one year of seniority with the same socio-economic level that the miner. The City of Lubumbashi is the second largest city of the Democratic Republic of the Congo the most populated after Kinshasa, its population would be around two million inhabitants according to the latest estimates. It is the economic capital of the Democratic Republic of the Congo; it is also the capital of the province of Katanga. It is designated as the Copperbelt capital because of the production of the copper and is part of the Copper Belt of Africa [11]. This study was conducted in 2015 on a period of 2 months, from 1 May to 31 June 2015 in the village Lwisha which is located $80 \mathrm{~km}$ from the city of Lubumbashi on the road Likasi, in the territory of Kambove, District of the High Katanga. The size of the sample was a function of the number of the miner that we found on the place of service when our descent. As well there has been an exhaustive sampling to arrive to have all the miners of the Lwisa village. As well, our sample was composed of 122 controls and 104 selected miner exhaustively. We have been excluded all miners and controls with: less than 6 months of seniority, taking immunosuppressive treatment, a corticosteroid, included in another study or having refused to complete the informed consent.

\subsection{The Variables}

The study analyzed the data: socio-anthropometric, respiratory symptoms using a standardized questionnaire and a physical examination. The workers have been consulted on the place of their respective work. The information obtained concerning the health of miners and controls, has been collected on the basis of a questionnaire Standardized Respiratory comprising different headings of questionnaires including: a general questionnaire on the sociodemographic characteristics (age, sex, educational level, smoking habits, alcohol, seniority at work, occupational history and exposures outside work), a questionnaire of the International Union Against Tuberculosis and Respiratory Diseases (IUATLD) Bronchial Symptoms (1986) [12], a questionnaire on the allergic rhinitis of Annesi-Maesano [13]. In addition, it is important to mention that all of the miner do not use of material for protection in the exercise of their profession.

\subsection{Definitions of Targeted Pathologies}

We have considered as asthmatic, any subject having of paroxysmal crises of dyspnoeasibilante, of repeated episodes of wheezing in the chest or a spasmodic cough with respiratory discomfort to repetition. Of rhinitis have been classically defined on the basis of a quantitative score SFAR (Score for allergic rhinitis) [13]. The Ocular pruritus, red- 
ness of the eyes and the watery symptoms were sought to define the conjunctivitis. The weight has been measured by means of a balance calibrated and verified, the size was measured with a spacer. The recording of the blood pressure by means of an electronic device (OMRON Hem8402) was carried out at the left arm argued to the height of the heart, the topic is being rested for at least 10 minutes in sitting position. The confidentiality and anonymity were guaranteed to persons who have answered the questions. The investigators have benefited from a training in advance and the investigation has been carried out by direct maintenance between the investigators and the persons included in the study.

\subsection{Consideration of Ethics}

The informed consent of subjects has been obtained from the later. The Ethics Committee of the University of Lubumbashi had given its agreement for the conduct of this study.

\subsection{Statistical Analyzes}

The Excel software has allowed the encoding of all data. Analyzes were performed using the SPSS software 21.0 (SPSS Inc., Chicago, it, USA). The statistical study has rested on the test " $\mathrm{T}$ " of the student for the comparison of the averages and the Fisher exact test for the relative proportions anthropometric characteristics and sociodemographic. For the qualitative variables such as respiratory symptoms, cross-tabulation was conducted with an estimate of the values of the Chi square and the relative risk. On the other hand, to determine the association between the characteristics of the miners and respiratory symptoms reported, a multi analysis varied with the test of logistic regression was privileged. This model has estimated the strength of association by a report of prevalence (OR) and its 95\% confidence interval (C.I. 95\%). The threshold of significance chosen corresponds to a value of $p<0.05$.

\section{Results}

\subsection{Anthropometric Characteristics, Clinical and Socio-Demographic}

Table 1 shows that the sample was made up of 104 miners and 122 controls to which the average age was $34.07 \pm 8.05$ and $35.05 \pm 10.3$ among miners and controls, respectively. For the miners, seniority was $7.35 \pm 4$ years, whereas it was $9.69 \pm 8.8$ years among the controls. The duration of work was to $9.347 \pm 4.16$ hours/day for the miners against $8.97 \pm 1.05$ hours in the controls. The average body mass index of the miners was lower than that of the control group, either $22.06 \pm 2.31$ against $23 \pm 3.6$ in the control group. The systolic blood pressure (SBP) average of the miners was no different to that of the controls, either $114.81 \pm 10.97 \mathrm{mmHg}$ or $113.4 \pm 14.19 \mathrm{~mm} \mathrm{Hg}$, respectively $(p>0.05)$. Diastolic blood pressure (DBP) average of the miners was equal to that of the control group, $70.67 \pm 6.86 \mathrm{mmHg}$ against $69.3 \pm 10.57 \mathrm{mmHg}$, respectively $(p>$ $0.05)$. On the other hand, a high proportion (66.3\%) of the miners had a secondary level non-completed education. There had $0.8 \%$ of controls having completed their second- 
Table 1. Anthropometric characteristics, clinical and socio-demographic.

\begin{tabular}{ccc}
\hline Characteristics of Participants & Miners (n=104) & Controls (n= 122) \\
\hline $\begin{array}{c}\text { Anthropometric parameters, } \\
\text { clinical and those related to the work }\end{array}$ & Average +/- DS & Average +/- DS \\
Age (years) & $34.07 \pm 8.05$ & $35.05 \pm 10.3$ \\
Seniority (years) & $7.46 \pm 4$ & $9.69 \pm 8.77 \#$ \\
Duration of work (hours) & $9.47 \pm 4.16$ & $8.97 \pm 1.05$ \\
BMI & $22.06 \pm 2.31$ & $23 \pm 3.6 \#$ \\
PAS & $114.81 \pm 10.97$ & $113.4 \pm 14.19$ \\
PAD & $70.67 \pm 6.86$ & $69.3 \pm 10.57$ \\
Saciodemographic parameters & $\mathrm{N}(\%)$ & $\mathbf{N}(\%)$ \\
Yes & & $18(14.8)$ \\
Non & $68(65.4)^{*}$ & $104(85.2)$ \\
Tobacco & $36(34.6)$ & \\
Yes & & $5(4.1)$ \\
Non & $53(51.0)^{*}$ & $117(95.9)$ \\
Education & $51(49.0)$ & $35(41.0)$ \\
Primary School & & $71(58.2)$ \\
Secondary Non-completed & $34(32.7)$ & $1(1)$ \\
Secondary education completed & $69(66.3)$ & \\
\hline
\end{tabular}

${ }^{\star}$ Notes: \#, the value of $p$ less than 0.05 for the test " $\mathrm{t}$ " of student; ${ }^{*}, p$ value less to 0.001 for the Fisher exact test.

ary studies while only $1 \%$ of miners have been able to achieve this level. In addition, there were more of miners who took alcohol, $65.4 \%$ against $14.8 \%$ in the controls $(p<$ $0.05)$; regarding smoking, a relatively high proportion of miner $(51 \%)$ was smoker $(4.1 \%$ in the controls; $p<0.01)$.

\subsection{Prevalence of Respiratory Symptoms}

Table 2 shows the prevalence of respiratory symptoms in the miners and the control group. The miners have presented a prevalence of whistling from 5.08 times more and a prevalence of shortness of breath after effort of 8.21 times more that the controls $(p<$ $0.001)$. In addition, in this professional category with exposure to dust of ores, a prevalence of cough of 2.42 times more, a prevalence of asthma of 14.66 times more, a prevalence of eczema of 38.43 times more that the controls $(p<0.001)$ has been noted. In addition, symptoms such as the rhinitis $(20.2 \%$; $21 / 104)$ and conjunctivitis (16.3\%; 17/104) have been reported by the miners without significant difference compared to the control group.

\subsection{Association between the Characteristics of the Miners and Respiratory Symptoms with the Use of a Multi-Analysis Varied with the Aid of the Test of Logistic Regression with Adjustment for Age and Level of Education}

Table 3 shows that after adjustment, there is an association between all respiratory 
Table 2. Prevalence of respiratory symptoms.

\begin{tabular}{|c|c|c|c|c|c|}
\hline Symptoms & Miners $\mathrm{N}=104$ & Controls $\mathrm{N}=122$ & RP [IC 95\%] & $\mathrm{X}^{2}$ & $p$ \\
\hline Wheezing & $39(37.5)$ & $9(7.4)$ & 5.08 [2.58 - 9.99] & 30.45 & $<0.001$ \\
\hline Cough & $31(29.8)$ & $15(12.3)$ & $2.42[1.39-4.24]$ & 10.62 & 0.001 \\
\hline Rhinitis & $21(20.2)$ & $18(14.8)$ & $1.37[0.77-2.43]$ & 0.81 & 0.29 \\
\hline Conjunctivitis & $17(16.3)$ & $12(9.8)$ & $1.66[0.83-3.31]$ & 2.13 & 0.16 \\
\hline Eczema & $36(34.6)$ & $3(2.5)$ & $14.07[4.46-44.38]$ & 38.43 & $<0.001$ \\
\hline
\end{tabular}

RP: prevalence ratio; $x^{2}$ : chi Carre of Pearson; the values of $p$ indicate the levels of meanings $(p<0.05$ : significant difference)

Table 3. Association between the characteristics of the miners and respiratory symptoms with the use of logistic regression with adjustment for age and level of education.

\begin{tabular}{|c|c|c|c|c|c|c|c|c|c|c|}
\hline \multirow{2}{*}{ Parameters } & \multicolumn{2}{|l|}{ Wheezing } & \multicolumn{2}{|c|}{$\begin{array}{l}\text { Shortness of breath } \\
\text { after effort }\end{array}$} & \multicolumn{2}{|l|}{ Cough } & \multicolumn{2}{|l|}{ Asthma } & \multicolumn{2}{|l|}{ Eczema } \\
\hline & OR [IC 95\%] & $p^{*}$ & OR [IC 95\%] & $p^{*}$ & OR [IC 95\%] & $p^{*}$ & OR [IC 95\%] & $p^{*}$ & OR [IC 95\%] & $p^{*}$ \\
\hline \multicolumn{11}{|l|}{ Age } \\
\hline$\leq 30$ & $1.69[0.85-3.37]$ & 0.27 & $2.06[0.88-4.82]$ & 0.19 & $1.77[0.87-3.59]$ & 0.18 & $1.56[0.65-3.75]$ & 0.47 & $1[0.49-2.04]$ & 0.37 \\
\hline$>30$ & 1 & & 1 & & 1 & & 1 & & & \\
\hline \multicolumn{11}{|l|}{ Seniority } \\
\hline$\leq 8$ years & $0.93[0.49-1.76]$ & 0.41 & $1.53[0.71-3.31]$ & 0.43 & $1.45[0.75-2.82]$ & 0.31 & $1.3[0.57-2.95]$ & 0.95 & $1.15[0.57-2.3]$ & 0.93 \\
\hline$>8$ years & 1 & & 1 & & 1 & & 1 & & 1 & \\
\hline \multicolumn{11}{|l|}{ Duration of work } \\
\hline$\leq 12$ & $0.51[0.16-1.58]$ & 0.85 & $0.42[0.12-1.41]$ & 0.75 & $0.48[0.16-1.49]$ & 0.64 & $0.87[0.19-4.1]$ & 0.41 & $0.2[0.07-0.6]$ & 0.14 \\
\hline$>12$ & 1 & & 1 & & 1 & & 1 & & 1 & \\
\hline Non & 1 & & 1 & & 1 & & 1 & & 1 & \\
\hline $\begin{array}{l}\text { Profession } \\
\text { Miners } \\
\text { Controls }\end{array}$ & $\begin{array}{c}7.53[3.43-16.54] \\
1\end{array}$ & 0.002 & $\begin{array}{c}10.87[3.67- \\
32.21] \\
1\end{array}$ & 0.004 & $\begin{array}{c}3.03[1.53-6] \\
1\end{array}$ & 0.07 & $\begin{array}{c}18.98[4.37-82.41] \\
1\end{array}$ & 0.002 & $\begin{array}{c}21[6.23-70.77] \\
1\end{array}$ & 0.000 \\
\hline $\begin{array}{c}\text { Education } \\
\text { Completed primary } \\
\text { Secondary Non-and completed }\end{array}$ & $\begin{array}{c}0.72[0.36-1.42] \\
1\end{array}$ & 0.56 & $\begin{array}{c}0.74[0.33-1.64] \\
1\end{array}$ & 0.69 & $\begin{array}{c}1.11[0.57-2.16] \\
1\end{array}$ & 0.59 & $\begin{array}{c}0.83[0.35-1.93] \\
1\end{array}$ & $\begin{array}{c}0.9 \\
4\end{array}$ & $\begin{array}{c}0.94[0.46- \\
1.92] \\
1\end{array}$ & 0.8 \\
\hline
\end{tabular}

OR: Odds ratio; IC: interval of confidence; ${ }^{*}, p$ value adjusted less than 0.05 .

symptoms and the profession of miners except for the symptom cough. Thus, the miners have presented of whistles $(\mathrm{OR}=7.53)$, shortness of breath after effort $(\mathrm{OR}=$ $10.87)$, asthma $(\mathrm{OR}=18.98)$, eczema $(\mathrm{OR}=21)$ high compared to the control group $(p$ $<0.01)$. In addition, the Tobacco $(\mathrm{OR}=5.81)$ was associated with the shortness of breath $(p<0.05)$. 


\section{Discussion}

The purpose of this study was to determine the state of the respiratory health of artisanal miners exposed to dust of ores in the career of the Lwisha village located $80 \mathrm{~km}$ from the city of Lubumbashi. Our study found that $100 \%$ of workers have not of material for personal protection and do not use some equipments or strategies of prevention against the silicosis and other occupational diseases in the exercise of their profession. Our finding is not different from the one makes by Aliyu [11] to the north of Nigeria and by Yadav [12] to India in the careers of the stones. The lack of use of the materials and the protective means of our artisanal miners could be probably to the low level of education (32.7\% primary and $66.3 \%$ incomplete secondary). It is in conformity with the observations made by Hentschel [13] which has found that most workers of the artisanal mining sector did not have an education and had a low social economic level.

In our study, the Artisanal miners handle daily for more than 12 hours, without rest;large quantities of ores and without means of protection. Our investigation has found a significantly elevated prevalence of respiratory symptoms in the miners by report to the non-exposed group. Concerning the respiratory symptoms, the data collected by the examination revealed the presence of a large number of complaints among the miners and this in a meaningful way compared to the control group, with a predominance of respiratory signs such as wheezing $(37.5 \%)$, crisis of shortness of breath after effort (26.9\%), cough (29.8\%), asthma (24\%), rhinitis (20.2\%), conjunctivitis (16.3\%) and eczema (34.6\%). Indeed, our results are comparable to those found by some authors in Iran [14], Brazil [15] and Nigeria [16]. The prevalence of wheezing and the crisis of shortness of breath after effort were lower than in relation to the results of the studies made by Singh [17], Abdel-Rasoul [18], Singh [19], and Nurul [20] in the middle of the dust due to metals. But it was superior to the prevalence found by Ehsan [21] among the workers of the cement plant in Iran. In addition, the prevalence of asthma found in this work was $24 \%$ in the exposed, far exceeding that reported by Bonny [22], Chun-Yang [23], Laraqui [24] and Hafiz [25]; this suggests that asthma as pathology is far from being a rare condition among artisanal miners and could constitute a major public health problem among the miners, in particular in the city of Lubumbashi. Moreover, in our study, the rate of rhinitis is lower than that found by Laraqui (49.3\%) in Morocco [24]. Some data published on the subject of the relationship between the rhinitis and asthma in the population show a frequent association of two diseases, rhinitis often preceding the onset of asthma [26] [27]. It has been difficult in our study to determine which symptom was the first. Concerning the dermatological problems, our investigation reveals a rate of $34.6 \%$ of eczemas among miner's handicrafts which is higher than that found in Nigeria [16]. As well, the problems of skin irritation are also present in our miners of our environment. These dermatologic lesions likely have a multifactorial etiology: chemical, physical, mycosis and allergic [16] [28] [29]. Nowadays, it is known that an exposure to dust causes dermatitis and affects the health [30]. On the other hand, our study found a strong association between the pro- 
fession and respiratory symptoms such as: wheezing, shortness of breath after effort, asthma and eczema. The tobacco has been associated with the presence of the shortness of breath after effort. And this is not new in our observation, because several studies show that the use of tobacco and/or drugs can have an aggravator effect on the respiratory pathologies of agents exposed to dust [31] [32]. This study has a few weaknesses. First, it's the lack of an adequate exploration of the respiratory function (spirometry, peak flow, FNO) and the x-ray of the thorax. Second, the effect of the inherent healthy worker to the transverse epidemiological model constitutes a bias of selection. It can also lead to under estimate in our study the prevalence of clinical symptoms and the importance of the occupational risk in general.

However, it is important that these small businesses are recognized by the Congolese government in order to impose occupational medical services applied as well as the respect of the standards required in the Congolese Labor Code in the matter of work place exposure. Under-developed countries like the DR Congo are fighting to reduce air pollution and do not have extensive studies to care for patient admitted in Hospitals in case of exposure to atmospheric particles because the majority of the population does not have access to health care. It will be important to conduct studies with a large population and in all the different quarries where the population is exposed.

\section{Conclusion}

The investigation reveals the poor conditions of work and the lack of protective equipment to staff of artisanal miners Congolese. In the majority of cases, the respiratory symptoms of miners could be in direct relationship with their profession by reporting to the control group. It is very important to organize a specialized teaching of occupational medicine which can train doctors with proven expertise to address the enormous need for qualified personnel in this field; but also to increase the level of prevention, monitoring of this population at risk.

\section{References}

[1] Artisanal and Small-Scale Mining: An Emerging Opportunity for Sustainable Development, 2008.

[2] Aliyu, A.A. and Shehu, A.U. (2006) Occupational Hazards and Safety Measures among Stone Quarry Workers in Northern Nigerian. Nigerian Medical Practitioner, 50, 42-47.

[3] Hentschel, T., Hruschka, F. and Priester, M. (2002) Global Report on Artisanal and Small Scale Mining. Mining, Minerals and Sustainable Development, No. 70, 3.

[4] Aigbedion, I. and Iyayi, S.E. (2007) Environmental Effect of Mineral Exploitation in Nigeria. International Journal of Physical Sciences, 2, 33-38.

[5] Fatusi, A. and Erbabor, G. (1996) Occupational Health Status of Sawmill Workers in Nigeria. Journal of the Royal Society of Health, 116, 232-236. https://doi.org/10.1177/146642409611600408

[6] Olusegun, O., Adeniyi, A. and Adeola, G.T. (2009) Impact of Granite Quarrying on the Health of Workers and Nearby Residents in Abeokuta Ogun State, Nigeria. Ethiopian Journal of Environmental Studies and Management, 2, 1-11. 
[7] COPIREP. Rapport final du Séminaire sur l'exploitation minière artisanale au Katanga, du 22 au 23 juin 2004.

[8] Elenge Molayi, M. (2008) Législation minière, environnement et protection de la santé du travail des artisans miniers en R D Congo. Congo-Afrique, Kinshasa, 373-390.

[9] Park, K. (2007) Occupational Health In: Park's Textbook of Preventive and Social Medicine, 18th Ed., M/S Banarsidas Bhanot, Jabalpur, 608-610.

[10] Urom, S.E., Antai, A.B. and Osim, E.E. (2004) Symptoms and Lung Function Values in Nigerian Men and Women Exposed to Dust Generated from Crushing of Granite Rocks in Calabar, Nigeria. Nigerian Journal of Physiological Sciences, 19, 41-47.

[11] Aliyu, A.A. and Shehu, A.U. (2006) Occupational Hazards and Safety Measures among Stone Quarry Workers in Northern Nigerian. Nigerian Medical Practitioner, 50, 42-47.

[12] Yadav, S.P., Anand, P.K. and Singh, H. (2011) Awareness and Practices about Silicosis among the Sandstone Quarry Workers in Desert Ecology of Jodhpur, Rajasthan, India. Journal of Human Ecology, 33, 191-196.

[13] Hentschel, T., Hruschka, F. and Priester, M. (2002) Global Report on Artisanal and Small scale Mining. Mining, Minerals and Sustainable Development.

[14] Mashaallah, A., Mohammad, R.Z. and Ali, A.F. (2006) Prevalence of Silicosis among Workers in Stone-Cutter and Silica Powder Production Factories. Tanaffos, 5, 31-36.

[15] Lemele, A., de Araujo, A.J., Lapa, S.J.R., et al. (1994) Respiratory Symptoms and Spirometric Tests of Quarry Workers in Rio de Janeiro. Revista da Associação Médica Brasileira, 40, 23-35.

[16] Nwibo, A.N., Ugwuja, E.I., Nwambeke, N.O., Emelumadu, O.F. and Ogbonnaya, L.U. (2012) Pulmonary Problems among Quarry Workers of Stone Crushing Industrial Site at Umuoghara, EbonyiState, Nigeria. Indian Journal of Occupational and Environmental Medicine, 3, 178-185.

[17] Singh, P.L., Bhardwaj, A. and Deepak, K.K. (2013) Occupational Exposure to Respirable Suspended Particulate Matter and Lung Functions Deteriorationamong Steel Workers: An Exploratory Study in India. ISRN Public Health, 2013, Article ID: 325410. https://doi.org/10.1155/2013/325410

[18] Abdel-Rasoul, G.M., Mahrous, O.A.E., Abou Salem, M.E., Al-Batanony, M.A. and llam, H.K. (2009) Auditory and Respiratory Health in an Iron and Steel Factory. Zagazig Journal of Occupational Health and Safety, 2, 1-10.

[19] Singh, P.L., Bhardwaj, A. and Deepak, K.K. (2011) Respirable Suspended Particulate Matter (RSPM) and Respiratory Symptoms among Casting Industry Workers: An Exploratory Study in Northern India. International Journal of Advanced Engineering Technology, 2, 251-259.

[20] Hamzah, N., Tamrin, S. and Ismail, N. (2013) Metal Dust Exposure and Respiratory Symptoms among Steel Workers: A Dose-Response Relationship. International Journal of Collaborative Research on Internal Medicine \& Public Health, 7, 24-39.

[21] Rafeemanesh, E., Alizadeh, A., AfshariSaleh, L. and Zakeri, H. (2015) A Study on Respiratory Problems and Pulmonary Function Indexes among Cement Industry Workers in Mashhad, Iran. Medycyna Pracy, 66, 471-477. https://doi.org/10.13075/mp.5893.00115

[22] Bonny, J.S., Pigearias, B., Lonsdorfer, J., Cantineau, A. and Curtes, J.P. (1988) Maladies respiratoires et fonction ventilatoire chez les ouvriers d'une cimenterie à Abidjan (Cote d'Ivoire). Archives des Maladies Professionnelles, 49, 455-460.

[23] Yang, C.Y., Huang, C.C., Chiu, H.F., Chiu, J.F., Lan, S.J. and Ko, Y.C. (1996) Effects of Oc- 
cupational Dust Exposure on the Respiratory Health of Portland Cement Workers. Journal of Toxicology and Environmental Health, 49, 581-588.

https://doi.org/10.1080/009841096160637

[24] Laraqui Hossini, C.-H., Laraqui Hossini, O., Rahhali, A.-E., Tripodi, D., Caubet Belamallem, I., Verger, C., Hakam, K. and Alaoui Yazidi, A. (2002) Symptomes respi- ratoires et troubles ventilatoires chez les travailleurs dans une cimenterie au Maroc. Revue des Maladies Respiratoires, 19, 183-189.

[25] Ahmed, H. and Abdullah, A. (2012) Dust Exposure and Respiratory Symptoms among Cement Factory Workers in the United Arab Emirates. Industrial Health, 50, 214-222. https://doi.org/10.2486/indhealth.MS1320

[26] Shaaban, R., et al. (2008) Rhinitis and Onset of Asthma: A Longitudinal Population-Based Study. Lancet, 372, 1049-1057. https://doi.org/10.1016/S0140-6736(08)61446-4

[27] Bousquet, J., Van Cauwenberge, P. and Khaltaev, N. (2001) Allergic Rhinitis and Its Impact on Asthma. Journal of Allergy and Clinical Immunology, 108, S147-S334. https://doi.org/10.1067/mai.2001.118891

[28] Babatunde, O.A., Ayodele, L.M., Elegbede, O.E., Babatunde, O.O., Ojo, O.J., et al. (2013) Practice of Occupational Safety among Artisanal Miners in a Rural Community in Southwest Nigeria. International Journal of Science, Environment and Technology, 2, 622-633.

[29] Geraut, C. (1995) Maçons et coffreurs.In Geraut C. In: Geraut, C., Ed., L'essentiel des pathologies professionnelles, Ellipses, Paris, 238-243.

[30] World Health Organization (1999) Prevention and Control Exchange: Hazard Prevention and Control in the Work Environment. WHO, Geneva, 219.

[31] Ulm, K., Gerein, P., Eigenthaler, J., Schmidt, S. and Ehnes, H. (2004) Silica, Silicosis and Lung-Cancer: Results from a Cohort Study in the Stone and Quarry Industry. International Archives of Occupational and Environmental Health, 77, 313-318. https://doi.org/10.1007/s00420-004-0513-6

[32] Ulm, K., Waschulzik, B., Ehnes, H., Guldner, K., Thomasson, B., Schwebig, A., et al. (1999) Silica Dust and Lung Cancer in the German Stone, Quarrying, and Ceramics Industries: Results of a Case-Control Study. Thorax, 54, 347-351. https://doi.org/10.1136/thx.54.4.347

Submit or recommend next manuscript to OALib Journal and we will provide best service for you:

- Publication frequency: Monthly

- 9 subject areas of science, technology and medicine

- Fair and rigorous peer-review system

- Fast publication process

- Article promotion in various social networking sites (LinkedIn, Facebook, Twitter, etc.)

- Maximum dissemination of your research work

Submit Your Paper Online: Click Here to Submit

Or Contact service@oalib.com 